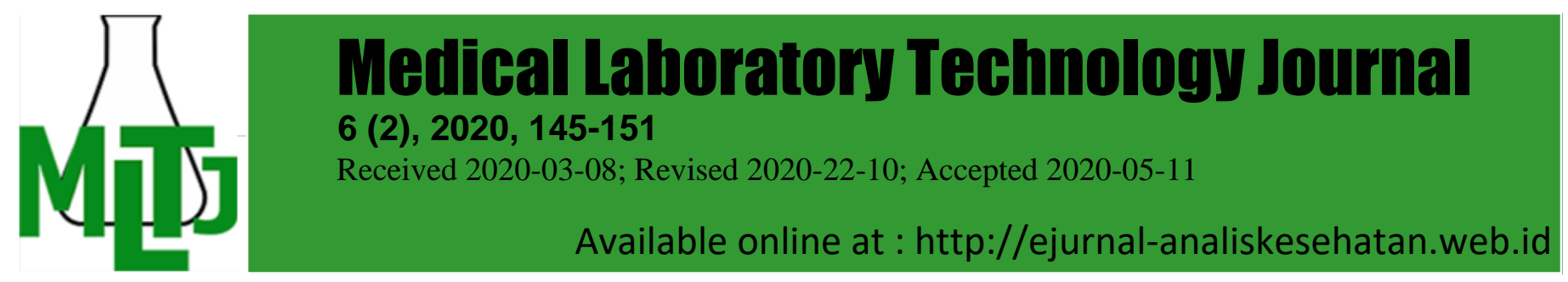

\title{
Increased Mean Platelet Volume (MPV) in Patients with ST Elevation Myocardial Infarction (STEMI) Compared to Non-ST Elevation Myocardial Infarction (NSTEMI) Patients
}

\author{
*Tri Ratnaningsih, Istiqomah \\ Department of Clinical Pathology and Laboratory Medicine, Faculty of Medicine, \\ Public Health, and Nursing Gadjah Mada University, Farmako Street, Depok, \\ Sleman, Yogyakarta Special Region, Indonesia \\ *Email: triratnaningsih@ugm.ac.id \\ DOI: $10.31964 / \mathrm{mltj} . v 6 \mathrm{i} 2.320$
}

\begin{abstract}
Platelets are known to have a role major in the pathogenesis of atherothrombosis. More giant and hyperreactive platelets accelerate the formation of an intracoronary thrombus. An increased MPV as an indicator of larger and more reactive platelets represents a risk factor for overall vascular mortality, including myocardial infarction. This study aimed to identify the increase of Mean Platelet Volume in Patients with Acute Coronary Syndromes, especially in ST-elevation myocardial infarction and Non-ST-elevation myocardial infarction. Thus this parameter can be used as consideration for diagnosis and treatment decisions. This research is an analytic observational with a cross-sectional method. The subjects were patients with STEMI and NSTEMI who were hospitalized in ICCU Dr.Sardjito Hospital Yogyakarta. Thirty-four subjects STEMI and NSTEMI patients at Dr. Sardjito Hospital, consisting of 28 males $(82,35 \%)$ and six women $(17,65 \%)$ with a mean age of $55,5 \pm$ 10,3 years. The results showed that MPV in AMI was higher in patients with STEMI than NSTEMI, but this difference is not significant $(p=0,091)$. This study concludes that MPV to be higher in patients with STEMI compared to NSTEMI. MPV may be used as a marker of myocardial infarction in clinically appropriate situations.
\end{abstract}

Keywords: Mean Platelet Volume, Acute Coronary Syndromes, ST-elevation myocardial infarction, Non-ST-elevation myocardial infarction

\section{INTRODUCTION}

Cardiovascular disease is a significant public health problem because the global number of deaths has increased in the past decade. According to the World Health Organization, an estimated 17.9 million people died from CVDs in 2016, representing $31 \%$ of all global deaths (WHO, 2017). The mortality rate due to cardiovascular disease in Indonesia is increasing year by year. It reported that Coronary Heart Diseases (CHD) is a significant cause of death in Indonesia by $26.4 \%$, four times higher than death by cancer (Indonesian Heart Association, 2019). Individuals with comorbidities such as diabetes mellitus, dyslipidemia, or hypertension are at risk of developing cardiovascular disease.

Acute Coronary Syndrome (ACS) is a cardiovascular disease with acute manifestations due to coronary atheroma plaque rupture. This disease is related to changes in the plaque composition and thinning of the fibrous covering the plaque. This event will be followed by the process of platelet aggregation and activation of the coagulation pathway to form a platelet-rich thrombus (white thrombus). This thrombus will clog the coronary artery holes either in total or partially or become a micro Corresponding Author: Tri Ratnaningsih

Department of Clinical Pathology and Laboratory Medicine, Faculty of Medicine, Public Health, and Nursing Gadjah Mada University, Farmako Street, Depok, Sleman, Yogyakarta Special Region, Indonesia. Email: triratnaningsih@ugm.ac.id 
embolism that blocks more distal coronary arteries. The release of vasoactive substances also occurs, causing vasoconstriction, thereby aggravating coronary blood flow disruption. Decreased coronary blood flow causes myocardial ischemia. Oxygen supply that stops for approximately 20 minutes can cause the heart muscle to experience necrosis (myocardial infarction). The total occlusion of coronary arteries does not always cause myocardial infarction. Subtotal obstruction, accompanied by dynamic vasoconstriction, can cause ischemia and necrosis of heart muscle tissue. In addition to necrosis, the result of ischemia is impaired myocardial contractility, dysrhythmias, and ventricular remodeling (changes in shape, size, and function of the ventricles) (Irmalita et al., 2015).

Acute Coronary Syndrome based on history, physical examination, electrocardiogram (ECG) examination, and cardiac biomarker examination is divided into three types, namely ST-segment Elevation Myocardial Infarction (STEMI), NonST-segment Elevation Myocardial Infarction (NSTEMI), and Unstable Angina Pectoris (UAP) ). STEMI is an indicator of the total occlusion of coronary arteries. This situation requires revascularization to restore blood flow and myocardial reperfusion as soon as possible, medically using fibrinolytic agents or mechanically with primary percutaneous coronary intervention. STEMI is diagnosed if there is a complaint of acute angina pectoris accompanied by persistent ST-segment elevation in two contiguous leads of the electrocardiogram. NSTEMI and UAP are diagnosed if there is a complaint of acute angina pectoris without persistent ST-segment elevation in two contiguous leads of the electrocardiogram. ECG records can be in the form of STsegment depression, $T$ wave inversions, flat $T$ waves, pseudo-normalization $T$ waves, or even unchanged. UAP and NSTEMI are differentiated based on the incidence of myocardial infarction, which is characterized by an increase in cardiac biomarkers, which commonly used are Troponin I / T or CK-MB. If there is a significant increase in the cardiac biomarker examination results, the diagnosis becomes NSTEMI, while the UAP does not increase significantly. (Irmalita et al., 2015).

Platelets have an essential role in the formation of atherosclerotic plaque and pathogenesis of atherothrombosis. One of the platelet indices, namely platelet size (MPV), is a hemostasis physiological variable. Increased MPV values are used as a sign of large and reactive platelets. Large and reactive platelets accelerate the formation of thrombus in coronary arteries. Enhanced platelet aggregation is associated with unstable angina and myocardial infarction (Mumpuni et al., 2016). Platelet size is determined at the level of progenitor cells, namely megakaryocytes. Research has reported that cytokines such as interleukin-3 or interleukin-6 can influence megakaryocytes to produce larger and reactive platelets. This may illustrate the presence of a risk factor for overall vascular mortality, including myocardial infarction. Studies have reported that MPV increases before the event of acute myocardial infarction. MPV can be detected earlier compared to the specific and nonspecific myocardial infarction markers. MPV examination is a routine hematological examination and is available in most clinical laboratories to provide benefits in managing myocardial infarction (Manchanda et al., 2015). There are no consistent measurements used as a strong predictor of clinical deterioration in ACS. This study aims to determine the increase in the Mean Platelet Volume (MPV) in acute myocardial infarction patients, especially STEMI and NSTEMI in Dr. Sardjito Hospital Yogyakarta.

\section{MATERIALS AND METHOD}

This study is an observational analytic study with a retrospective design. The study was conducted at the Clinical Laboratory Installation Dr. Sardjito Hospital 
Yogyakarta from April 2014 to August 2014. The research subjects were STEMI and NSTEMI patients discharged from the ICCU Dr. Sardjito Hospital Yogyakarta based on a history of physical examination and electrocardiogram (ECG) examination. The inclusion criteria were: (1) patients with a diagnosis of STEMI or NSTEMI, (2) patients with onset $\leq 48$ hours, (3) patients aged $30-70$ years, and (3) patients who agreed to informed consent to participate in this study. Exclusion criteria were: (1) patients with stage $\mathrm{V}$ chronic renal failure, chronic heart failure with functional class NYHA III and above, cirrhosis of the liver, (2) patients with acute stroke, acute infections, sepsis, and venous thromboembolism, (3) patients who get intervention of primary percutaneous coronary or thrombolysis, and (4) patients suffering from a history of malignancy. The Ethical Committee of the Faculty of Medicine, Public Health, and Nursing Universitas Gadjah Mada approved this study (number KE/FK/0069/EC/2019).

MPV examination was carried out using venous blood samples with EDTA anticoagulant as much as $2 \mathrm{~mL}$ and examined using the ADVIA 120 Hematology Analyzer. Measurement was carried out immediately after collection, with a maximum time of 4 hours after sampling. During this time lag, the sample was placed at room temperature of $18^{\circ} \mathrm{C}-25^{\circ} \mathrm{C}$. Subjects were also examined for glucose and lipid profiles.

Data on the characteristics of research subjects is displayed descriptively. Characteristics of research subjects presented in the form of mean \pm standard deviations for normally distributed data and the median (minimum value - maximum value) for data that is not normally distributed, while normality tests for continuous data using Kolmogorov Smirnov analysis. Mann Whitney U-test was used as the average difference test between the two groups. The significance value was considered significant if the $p$-value $<0.05$. All calculations are done with a computerized system.

\section{RESULTS AND DISCUSSION}

A total of 34 STEMI and NSTEMI patients were obtained from this study with characteristics, as shown in Table 1.

Table 1. Basic characteristics of research subjects ( $n=34$ subjects)

\begin{tabular}{|c|c|}
\hline Variable & Value \\
\hline Age $\left(\right.$ year) ${ }^{\mathrm{a}}$ & $55.5 \pm 10.3$ \\
\hline \multicolumn{2}{|l|}{$\operatorname{Sex}(\%)$} \\
\hline - $\quad$ Man (28) & 82.35 \\
\hline - Female (6) & 17.65 \\
\hline Bodyweight (kg) & $63.4 \pm 9.3$ \\
\hline Body height $(\mathrm{cm})$ & $160.7 \pm 7.3$ \\
\hline Platelet $\left(\times 10^{\wedge} 3 / \mu \mathrm{L}\right)^{b}$ & $233(158-588)$ \\
\hline MPV (fL)a & $8.97 \pm 1.49$ \\
\hline Glucose ad random (mg/dL) ${ }^{b}$ & $144(87-528)$ \\
\hline Total Cholesterol $(\mathrm{mg} / \mathrm{dL})^{\mathrm{b}}$ & $181(104-483)$ \\
\hline Triglyceryde (mg/dL) ${ }^{b}$ & $114(42-312)$ \\
\hline $\mathrm{LDL}(\mathrm{mg} / \mathrm{dL})^{\mathrm{a}}$ & $131 \pm 34.2$ \\
\hline $\mathrm{HDL}(\mathrm{mg} / \mathrm{dL})^{\mathrm{b}}$ & $39(21-102)$ \\
\hline
\end{tabular}


The participant's mean age in this study was in the group of high risk category, according to the National Cholesterol Education Program (NCEP), which is more than 45 years for men and more than 55 years for women (Organization, 2016). Based on gender, most patients were male. This corresponds to the research by Araújo et al. (2018) that gets results from 379 STEMI patients, 278 patients (43\%) were male, and 101 (44.5\%) were female, from 494 NSTEMI patients, 368 patients (57\%) were male, and $126(55.5 \%)$ were female. That study obtained platelet and MPV value were 228.5 $\pm 59.2 \times 10^{3} / \mu \mathrm{L}$ and $8.9 \pm 0.8 \mathrm{fL}$. The average LDL was $131 \pm 34.2 \mathrm{mg} / \mathrm{dL}$, which is in the borderline-high classification according to the National Cholesterol Education Program (NCEP) (Organization, 2016). The subjects have risk factors on the lipid profile. The comparison of Mean Platelet Volume (MPV) based on risk factors for myocardial infarction showed in Table 2.

Table 2. Comparison of Mean Platelet Volume (MPV) Based on Risk Factors for Myocardial Infarction

\begin{tabular}{|c|c|c|c|c|}
\hline \multirow{2}{*}{\multicolumn{2}{|c|}{ Variable }} & \multicolumn{2}{|r|}{ MPV (fL) } & \multirow{2}{*}{$p$} \\
\hline & & $\mathrm{n}$ & Mean \pm SD & \\
\hline \multirow[t]{2}{*}{ Sex } & Man & 28 & $8.95 \pm 1.55$ & 0.957 \\
\hline & Female & 6 & $8.92 \pm 1.22$ & \\
\hline \multirow[t]{2}{*}{ Hypertension } & Yes & 19 & $8.48 \pm 1.50$ & $0.038^{*}$ \\
\hline & No & 15 & $9.53 \pm 1.26$ & \\
\hline \multirow[t]{2}{*}{ Diabetes Mellitus } & Yes & 10 & $8.66 \pm 1.50$ & 0.474 \\
\hline & No & 24 & $9.07 \pm 1.48$ & \\
\hline \multirow[t]{2}{*}{ Dyslipidemia } & Yes & 4 & $8.87 \pm 1.40$ & 0.919 \\
\hline & No & 11 & $8.96 \pm 1.51$ & \\
\hline \multirow[t]{2}{*}{ Smoking } & Yes & 15 & $9.09 \pm 1.46$ & 0.632 \\
\hline & No & 19 & $8.84 \pm 1.52$ & \\
\hline \multirow[t]{2}{*}{ Myocardial Infarct } & STEMI & 17 & $9.38 \pm 1.51$ & 0.091 \\
\hline & NSTEMI & 17 & $8.52 \pm 1.36$ & \\
\hline
\end{tabular}

Student T test; * Statistically significant $(\mathrm{p}<0.05)$

Differences in the mean of MPV by sex were found to be insignificant $(p=$ $0.957)$. This correspond to other study ${ }^{7}$ which found no association between sex and MPV value $(p=0.887)$. MPV values on patients with hypertension risk factor were higher than without hypertension $(p=0.038)$. Other studies also showed that MPV values were higher in patients with hypertension (Raiet al., 2016; Surgit et al., 2015). Agrawal et al. (2016) reported differences in the mean of MPV based on diabetes mellitus risk factor. However, this is different from the findings in the current study. Diabetes, due to a lack of insulin or insulin resistance, is considered a thrombotic state and can increase platelets activity. The mean of MPV was found to be higher in the patient without dyslipidemia compared to patients with dyslipidemia, but the difference was not statistically significant $(p=0.919)$. This is not following the study by Rai et al. (2016), which found the mean of MPV was higher in patients with dyslipidemia. The MPV in smokers was higher than in non-smokers but was insignificant $(p=0.632)$.

Hypertension can damage the arteries, thus hardening and narrowing. In contrast, in dyslipidemia, there is a buildup of fat that can reduce the arteries' diameter, causing occlusion of the blood vessels. People with diabetes with excess blood glucose also have a risk of myocardial infarction. Glucose in the blood can damage the endothelium of blood vessels, an inflammatory reaction occurs (deposition of 
platelets, macrophages, and fibrous tissue), causing thickening of blood vessels. Narrowing or occlusion of the coronary arteries can lead to ischemia and myocardial infarction. (3) Depression is also a risk factor for coronary heart disease. The mechanism of increased MPV in diabetes mellitus patients is still unclear. It said that hyperglycemia increases the production of thrombopoietin. IL-6 is also associated with insulin resistance in diabetes mellitus patients, so that IL-6 and thrombopoietin regulation influenced by diabetic conditions, such as hyperglycemia and hyperinsulinemia, which can increase platelet size.

In this study, MPV mean differences were higher in patients without risk factors for hypertension, diabetes mellitus, and dyslipidemia but were not statistically significant. These results differ from some studies, where MPV correlates with these risk factors (Ji et al., 2019; Inoue et al., 2020). Results that are not the same as other studies could be due to an insufficient number of subjects. We also did not analyze the level of depression in subjects, which may increase MPV. The depression status is associated with a high MPV level. MPV and depressants were found to have an independent association known to influence platelet activity (Bondade et al., 2018). Serotonin (5-hydroxytryptamine, or 5-HT) plays an important role in depression and more than $99 \%$ of the body's serotonin stored in platelets. Selective Serotonin Reuptake Inhibitors (SSRIs) are the most widely used class of antidepressants to treat depression. Platelets have biochemical similarities with central serotonergic neurons in the absorption, storage, and metabolism of serotonin. This has been used as a model to study the central nervous serotonin system's uptake and release. Serotonin is a relatively weak platelet agonist but can have potential in the process of platelet aggregation. Serotonin metabolism abnormalities can cause interference with the suppression of depression and abnormal platelets (Dietrich-Muszalska et al., 2016).

The MPV values in STEMI and NSTEMI patients in this study were $9.38 \pm 1.51$ and $8.52 \pm 1.36$, respectively. Based on MPV reference values of $7.11-9.11 \mathrm{fL}$ for the Advia 120 Hematology System, it found that the MPV value in STEMI patients was higher than the reference value, whereas, in NSTEMI patients, the MPV value was still in the normal range (LabPharm et al., 2016). The difference in the mean of MPV in acute myocardial infarct patients showed that MPV was higher in patients with STEMI than NSTEMI, but it was not significant ( $p=0.091)$. Thygesen et al. (2018) described that infarction is caused by coronary atherosclerosis and thrombus formation. Thrombocytes play an essential role in atherosclerosis and thrombosis. The ruptured or discharged atherosclerosis plaque will recruits thrombocyte to endothelial. The clogged blood vessels become entirely obstructed with newly formed thrombosis. Larger platelets have more potential for pro-thrombotic. Increased platelet volume is more reactive, with more advanced thromboxane A2 and serotonin (Ji et al., 2019).

If the research is carried out on more subjects, the MPV value's statistical significance will likely found in both conditions. MPV can be an additional diagnostic parameter in ACS diagnosis, but it is necessary to set a cut off value.

\section{CONCLUSION}

From the results of this study, it found that the average MPV in acute myocardial infarct patients showed that MPV was higher in STEMI compared to NSTEMI patients. MPV is a routine and direct laboratory measurement in most clinical laboratories to be used as an additional laboratory parameter of myocardial infarction in appropriate clinical situations. Further studies can be performed in a more robust group of patients with acute myocardial infarct and compared with healthy controls to confirm their use as additional parameter for diagnosis. 


\section{ACKNOWLEDGMENT}

Our thanks go to health workers for their cooperation in testing the blood samples, particularly from Clinical Laboratory Installation and ICCU of Dr. Sardjito Hospital Yogyakarta, who has facilitated this research.

\section{CONFLICT OF INTEREST}

The authors have no potential conflicts of interest regarding this study.

\section{REFERENCE}

Agrawal, B.K., Manchanda, B., Garg, A., Mittal, A., Mahajan, N.C., Agrawal, U. (2015). Mean Platelet Volume in Acute Myocardial Infarction: a Case-Controlled Study. Journal of Cardiovascular Research.; 1:4. Website:

https://www.researchgate.net/publication/282130697_Mean_platelet_volume_in _acute_myocardial_infarction_a_case-controlled_study

Anderson LL, French WJ, Peng SA, Vora AN, Henry TD, Roe MT, et al. (2015). Direct Transfer From the Referring Hospitals to the Catheterization Laboratory to Minimize Reperfusion Delays for Primary Percutaneous Coronary Intervention: Insights From the National Cardiovascular Data Registry. Circ Cardiovasc Interv [Internet]. [cited 2020 Oct 5];8(9). Website: https://www.ahajournals.org/ doi/epub/10.1161/CIRCINTERVENTIONS.114.0 2477

Araújo C, Laszczyńska O, Viana M, Melão F, Henriques A, Borges A, et al. (2018). Sex differences in presenting symptoms of acute coronary syndrome: the EPIHeart cohort study. BMJ Open, 8(2), e018798. Website:https://bmjopen.bmj.com/content/bmjopen/8/2/e018798.full.pdf

Avci E, Kiris T, Çelik A, Variş E, Esin FK, Köprülü D, et al. (2018). Prognostic value of rising mean platelet volume during hospitalization in patients with ST-segment elevation myocardial infarction treated with primary percutaneous coronary $\begin{array}{llll}\text { intervention. BMC Cardiovasc Disord, } & \text { 18(1), } 226 .\end{array}$ Website:https://bmccardiovascdisord.biomedcentral.com/articles/10.1186/s12872-018-0970-6

Bondade S, Supriya, Seema HS, Shivakumar BK. (2018). Mean Platelet Volume in Depression and Anxiety Disorder- a Hospital Based Case-control Study. Int Neuropsychiatr Dis J, 11(4), 1-8. Website: https://www.journalindj.com/index.php/INDJ/article/view/13889

Dietrich-Muszalska A, Wachowicz B. (2017). Platelet haemostatic function in psychiatric disorders: Effects of antidepressants and antipsychotic drugs. World $J$ Biol Psychiatry, 18(8), 564-74. Website: https://www.tandfonline.com/ doi/full/10.3109/15622975.2016.1155748

Executive Summary of the Third Report of the National Cholesterol Education Program (NCEP) Expert Panel on Detection, Evaluation, and Treatment of High Blood Cholesterol in Adult (Adult Treatment Panel III). (2016). Available in www.nhlbi.nih.gov. Website:https://jamanetwork.com/journals/ jama/articleabstract/193847

Huang H-L, Chen C-H, Kung C-T, Li Y-C, Sung P-H, You H-L, et al. (2019). Clinical utility of mean platelet volume and immature platelet fraction in acute coronary syndrome. Biomed J, 42(2),107-15. Website: https://www.sciencedirect.com/ science/article/pii/S2319417017304274

Indonesian Heart Associaciation. Hari Jantung Sedunia (World Heart Day): Your Heart is our heart too. (2019). Website:http://www.inaheart.org/news_and_events/ news/2019/9/26/press_release_world_heart_day_perki_2019 
Inoue H, Saito M, Kouchi K, Asahara S, Nakamura F, Kido Y. (2020). Association between mean platelet volume in the pathogenesis of type 2 diabetes mellitus and diabetic macrovascular complications in Japanese patients. J Diabetes Investig, 11(4), 938-45. Website: https://pubmed.ncbi.nlm.nih.gov/31833219/

Irmalita, Juzar, D.A., Andrianto, Setianto, B.Y., Tobing, D.P.L., Firman, D., Firdaus, I. (2015). Pedoman Tatalaksana Sindrom Koroner Akut. edisi ke-3. Perhimpunan Dokter Spesialis Kardiovaskuler Indonesia. Centra Communications, Jakarta. Website:http://www.inaheart.org/upload/image/Pedoman_tatalaksana_Sindrom Koroner_Akut_2015.pdf

Ji, S., Zhang, J., Fan, X., Wang, X., Ning, X., Zhang, B., Shi, H., Yan, H. (2019). The relationship between mean platelet volume and diabetic retinopathy: a systematic review and meta-analysis. Diabetol Metab Syndr 11, 25. Website: https://www.ncbi.nlm.nih.gov/pmc/articles/PMC6417244/pdf/13098_2019_Articl e_420.pdf

LabPhārm Kft, Sátoraljaújhely, Shemirani A. (2016). Preanalytical Factors Affecting the Mean Platelet Volume: a Review. Glob J Hematol Blood Transfus, 22;3(1), 19-22. Website: https://core.ac.uk/download/pdf/323167077.pdf

Manchanda, J., Potekar, R.M., Badiger, S., Tiwari A. (2015). The Study of Platelet Indices in Acute Coronary Syndromes. APALM. 02:A31-5. Website: https://www.pacificejournals.com/journal/index.php/apalm/article/view/139/pdf_ 42

Mumpuni H, Hariawan H, Krisdinarti L. (2016). Association Between Mean Platelet Volume (MPV) with Major Adverse Cardiovascular Events in Acute Coronary Syndrome during Hospitalization, 2(2), 9. Website: https://jurnal.ugm.ac.id/ jaci/article/view/22602/15060

Rai, A., Saidi, M., Salehi, N., Sahebjamei, F., Jalilian, M., Janjani, P. (2016). Comparison of Mean Platelet Volume in Acute Myocardial Infarction vs. Normal Coronary Angiography. Glob. J. Health Sci, 8(11). Website: http://www.ccsenet.org/journal/index.php/gjhs/article/view/59813

Surgit O, Pusuroglu H, Erturk M, Akgul O, Buturak A, Akkaya E, et al. (2015). Assessment of Mean Platelet Volume in Patients with Resistant Hypertension, Controlled Hypertension and Normotensives. Eurasian J Med, 47(2), 79-84. Website:https://www.ncbi.nlm.nih.gov/pmc/articles/PMC4494555/pdf/eajm-472-79.pdf

Thygesen K, Alpert JS, Jaffe AS, Chaitman BR, Bax JJ, Morrow DA, et al. (2018). Fourth Universal Definition of Myocardial Infarction (2018). J Am Coll Cardiol, 72(18), 2231-64. Website:https://www.sciencedirect.com/science/article/pii/ S0735109718369419?via\%3Dihub

World Health Organization. (2017). Cardiovascular diseases (CVDs), Fact Sheet, https://www.who.int/news-room/fact-sheets/detail/cardiovascular-diseases(cvds) 